\title{
Transmedia y moda: realismo y virtualidad en Chanel y Gaultier
}

\section{Transmedia and fashion: realism and virtuality in Chanel and Gaultier}

\author{
Manuel Viñas Limonchi. Universidad San Jorge (mvinas@usj.es)
}

Recibido: 27-03-2017 - Aceptado: 07-07-2017

\section{Resumen:}

La evolución de la industria de la moda en su parcela creativa depende, principalmente, del aporte estilístico que realiza el diseñador a cargo de la ideación y manufactura del producto, así como de su exhibición teatralizada y/o mediática. Ese mismo producto encuentra en el apartado tecnológico de la comunicación la justificación idónea para su expansión artística y persuasiva. En este artículo se abordará una revisión de recursos, especialmente de naturaleza iconográfica, que favorecen el emplazamiento de esta vertiente creativa dentro de los dominios de la narrativa transmedia. Un análisis constatado en clave publicitaria mediante la dirección de arte de dos autores, Lagerfeld y Gaultier, que plantean en sus intervenciones una migración de contenidos a distintos medios como complemento a la performance natural que se desenvuelve en la pasarela.

\section{Palabras Clave:}

Transmedia; moda; diseño; publicidad; creatividad.

\section{Abstract:}

The evolution of the fashion industry in the area of creativity depends mainly on the stylistic contribution made by the fashion designer responsible for the conception and manufacture of the final product, as well as of its dramatized show and/or media exhibition. This same product finds suitable mechanisms for its artistic and influential expansion in the technological area of communication. This article addresses a review of resources, mainly of an iconographic nature, that will indeed favour the placement of this creative aspect within the domain of the transmedia narrative. This is an analysis validated at the advertising level through the art direction of two fashion designers, Lagerfeld and Gaultier, who suggest in their proposals a migration of content to different media as a complement to the natural performance that unfolds on the fashion catwalk.

\section{Keywords:}

Transmedia, fashion, design, advertising, creativity. 


\section{Introducción. La moda: arte, diseño y comunicación}

"El hombre que en la moda solo ve moda, es un tonto". Esta frase lapidaria, pronunciada por un ilustre novelista, Honoré de Balzac, justifica la realidad más objetiva que hoy, en los primeros lustros del siglo XXI, admite el diseño de moda. Una disciplina, cuya permanente evolución se revela tanto en el taller del creador como en el marco expositivo del producto, mediatizando, en muchos casos, la percepción de este que experimenta el propio consumidor.

Aunque para G. Lipovetsky (2009: 9) "la moda es celebrada en el museo y relegada al trastero de las preocupaciones intelectuales reales", su conversión en industria -textil- supone ser asistida por múltiples áreas del conocimiento humano, que contribuyen a su desarrollo en fines creativos, así como en la búsqueda y el registro de tendencias socioculturales valiéndose de eficientes técnicas artísticas y de marketing. Una mercantilización, contra la que se "rebela" V. Steel, directora del Fashion Institute of Technology: "Parece que estemos hablando de la hija bastarda del capitalismo y de la vanidad femenina. Pero, de lo que trata este debate en realidad es de nuestra lucha por ocupar el lugar que merecemos en el mundo de las artes" (Torrecillas, 2015).

Seguramente, el arte ha sido, a lo largo del tiempo, el principal valedor estilístico de la creatividad que recubre el vestidor de esta disciplina, actuando como fuente de inspiración empleada por el autor y -en muchos casos- como "excusa formal" que argumentaba para exhibir la vertiente más iconoclasta de su estilo. Basta mencionar nombres como Chanel o Louboutin, para que en la retina del consumidor se proyecte el tweed escocés de Mademoiselle Chanel o el rojo carmín del genio del stiletto.

Esa armonía natural entre arte y moda se aleja, sin embargo, del testimonio que expresan algunos de los próceres de la disciplina, como A. Arzuaga (2001), para quien "el diseño de moda no es propiamente un arte. La moda está marcada por la estacionalidad. Lo efímero de su naturaleza y su carácter seriado hacen que se aleje del concepto de arte. Pero el arte, especialmente el arte moderno, influye de un modo claro en la moda".

Ahora bien, como afirma R. König, "la moda es un fenómeno totalmente social. Obviamente, no solo interesa la indumentaria, sino también las formas, los lenguajes y los gestos" (Pérez et al., 1992: 61). Argumento este que incorpora un nuevo interlocutor en el discurso, la comunicación, teniendo en cuenta que "la moda es examinada como un instrumento de comunicación práctico que exterioriza valores internos de los individuos" (Jiménez, 2008: 62).

Una comunicación conformada a través de instrumentos y lenguajes multimedia, encargados de generar y expandir las nuevas identidades del producto comunicativo, especialmente en el plano persuasivo. No en vano, "la publicidad y la moda (entendida esta última como un todo verbal, visual y real) son dos sistemas semióticos más o menos formalizables que, en la actualidad, se complementan a la perfección y que confluyen en la publicidad gráfica específica de productos del sector de la ropa y los complementos" (Alvarado, 2008: 124). 
En este punto, cabría citar una disciplina habilitada para separar arte y comunicación, interviniendo, paradójicamente, como proceso creativo transversal a ambas áreas: el diseño. Para W. Wong (1991: 9) "el diseño es un proceso de creación visual con un propósito. A diferencia de la pintura y de la escultura, que son la realización de las visiones personales y los sueños del artista, el diseño descubre exigencias prácticas, debiendo trasladar un mensaje prefijado". Así, en la génesis del proyecto, el diseño conceptual se convierte en la base ilustrativa y totalmente gestual del patronaje. En fases posteriores, su esquematización, fruto de la entrada de "nueva información, así como de los resultados del análisis de rendimiento, duración, coste, fiabilidad y facilidad de manejo" (Pipes, 2008: 115-116) del producto, estipula una tecnificación que comporta la inclusión del diseño de moda dentro de una matriz mayor, el diseño industrial.

Focalizando en el ámbito creativo de la moda, será el lenguaje visual empleado en las tres grandes áreas del diseño (gráfico/ editorial, industrial y urbanístico) el que module, a partir de ahora, este discurso. Un lenguaje que acoge modismos plenamente integrados en las sistemáticas TIC, siendo implementado en la creación y/o difusión del producto con ayuda de las herramientas propias de las vanguardias electrónicas para convertirse en un recurso idóneo del sumario transmedia.

\subsection{Método y ámbito. Transmedia y moda: compartiendo pasarela}

El lenguaje visual propio del diseño, descrito por D. Dondis (2004: 206) como un "medio de expresión y de comunicación y, por tanto, como un sistema paralelo a la comunicación visual”, es asistido en las fases proyectuales por mecanismos físicos que intermedian entre la actividad creativa del autor y la reflexiva del usuario. De este modo, al método de representación volumétrico y espacial más clásico, la perspectiva, se suma una sistemática gráfica, la estereoscopía, y una división tecnológica, la realidad virtual, generando un marco discursivo en torno a la percepción visual y su intervención en disciplinas donde la creatividad impulsa la ideación, el desarrollo y la posible difusión del producto.

Un discurso, en este caso, ubicado en los territorios digitales, donde el término transmedia se enuncia como argumento y no necesariamente como plataforma de intermediación comunicativa dispuesta entre canales y formatos mediáticos. Un contexto, en síntesis, en el que cobra un extraordinario protagonismo la máxima de M. McLuhan que reduce nuestra definición de arte a lo que él considera que son artilugios especializados para realzar la percepción humana.

Sin duda, el alcance divulgativo que experimenta hoy la parcela creativa de la moda, tratado como indicio temático de este ensayo, converge en ese dominio mediático en el que evolucionan diferentes formatos y géneros audiovisuales arraigados en disciplinas de la comunicación y el arte, como pueda ser la publicidad y el cine. Circunstancia que permite que el fin expositivo del producto no se restrinja estrictamente a una ceremonia consumada en la pasarela física del evento, ampliándose, de este modo, a los conductos y soportes digitales como el verdadero argumento de una colección-de una obra- cada vez más teatralizada en su representación.

Esa evidente expansión de la obra a otros espacios es planteada por M. Alvarado (2008:118), cuando argumenta que "las galas musicales o cinematográficas son un desfile de moda elevado a la quintaesencia, hasta el punto de que es difícil saber 
si la 'alfombra roja' es la entrada a otro lugar o un lugar en sí por el que desfilan, desvestidas de su condición de actrices, maniquíes diseñadas centímetro a centímetro". Una metáfora espacial que el propio Alvarado (2008: 132) traslada a la vertiente persuasiva más icónica, afirmando que "los anuncios de moda son silenciosos en lo verbal, pero visualmente ruidosos".

Según Lipovetsky (2009: 237), “con las operaciones multimedia se ha puesto en práctica una cierta 'racionalización' de la moda: no porque la moda deba ser desde ahora dirigida y controlada exhaustivamente -lo cual no tiene ningún sentido-, sino porque cada producción funciona como publicidad con respecto a otra". Auténtica filosofía transmedia.

En las primeras décadas del siglo xx, las grandes revistas de la época, como Vogue o Vanity Fair (editadas por Condé Nast Publications), fueron los principales enlaces cross-media entre la industria de la moda y sus consumidores. Las creaciones, plasmadas entonces en formato fotográfico por E. Steichen, Man Ray o E. Blumenfels, encontraban un hueco en las galerías; siendo que la "musealización" de la fotografía -su verdadera exhibición- se llevaba a cabo en las páginas de las citadas publicaciones. Si bien, como indica T. Bezzola (2008: 197), "un pedazo de tela nunca logrará evocar el espíritu del momento en el que fue creado, las imágenes de los mejores fotógrafos de moda del siglo XX, especialmente las recogidas en Vogue, son dignas del Louvre". Alegato, que contradice a Charles F. Worth ("padre" de la alta costura), quien aseguraba que "iun vestido no vale un cuadro!”.

Un siglo después, la codificación de la información mediante el uso de dispositivos y métodos creativos de naturaleza transmedia pone de manifiesto la contribución de las disciplinas artísticas -junto con los recursos digitales- en el desarrollo de heterogéneos canales dispuestos para la expansión argumental de la obra.

Hoy, la performance que rodea a la escenografía de los desfiles en las grandes citas de la moda internacional asume matices narrativos y técnicos que la convierten en un nuevo e interesante arquetipo transmedia. Un paradigma comunicativo destinado a la difusión objetiva y persuasiva de un producto -textil-, que se emplaza en un contexto figurado de objetos y sonidos, con un espectador plenamente integrado en la composición, difundido sincrónicamente -así como "enlatado"en los canales de la red y/o televisión y argumentado en otros medios digitales más atemporales, como pueda ser un blog de moda. Una secuencia de razones, cuyo resultado opera en términos de comunicación y moda, con unos sumandos (pasarela física/virtual + espectador/usuario + soporte/medio) que actúan coherentemente en la recreación de la intervención planteada. Verdadera narrativa transmedia.

De manera prácticamente simultánea al nacimiento del transmedia storytelling, uno de los grandes modistos del momento, T. Mugler, acogía en su territorio creativo el ya evolucionado potencial de la comunicación asistida por la tecnología digital, presentando su Thierry Mugler's Fashion Show en la edición de SIGGRAPH celebrada en 1998. Un proyecto impulsado en colaboración con Kinetix y REM Infografica, en el que se recreaba un desfile de moda virtual mediante simulaciones 3D empleando la iconografía propia de la ciencia ficción y el cine que Mugler recoge en su obra. 
En esta propuesta del modisto francés, el movimiento del maniquí y la detección de colisiones aplicada a la tela gracias a innovadoras técnicas de modelado, animación y renderizado tridimensional, introducían una interesante vía creativa y de difusión online dentro de los canales clásicos de producción y divulgación de eventos de esta naturaleza. No obstante, pese a este indiscutible avance en el campo de la moda y la comunicación, algunos críticos, como S. Singier (1998), admitían "que, aunque el efecto de animación de la tela es muy cercano a la realidad, el encanto que supone su recreación por parte de un modelo real (que normalmente admiramos en una presentación de este tipo) no se ha integrado todavía en la programación".

En 1999, alentados, en cierto modo, por la interesante propuesta de Mugler, los fundadores de Charmed Technology Inc., A. Ligthman y K. Barillova, presentaban en Nueva York y Hong Kong su proyecto Brave New Unwired World. Un año después, esta misma compañía introducía en Londres una fascinante muestra de corte futurista denominada The Brave New Unwired World Fashion Technology Show. En tan peculiar pasarela se podía contemplar "ropa equipada con redes digitales, desarrollada gracias a la alianza suscrita entonces entre la firma de moda Levi's y la empresa de electrónica Philips" (BBC, 2000). Surgía el concepto wearable computer.

Estas y otras iniciativas análogas favorecieron el avance de un renovado modelo creativo y comunicativo que fusionaba moda y tecnología, lanzando inéditas consignas técnicas y estéticas sobre ese cosmos cibercultural que prorrumpía en el nuevo milenio. El usuario, que comenzaba a estar plena y permanentemente interconectado, se incorporaba a este nuevo escenario, manejando una metodología e instrumentación enraizadas en el dominio electrónico. Los mecanismos digitales se incorporaban a la vestimenta, amparándose especialmente en las teorías sobre tecnología existencial desarrolladas a finales de 1970 por S. Mann (Universidad de Toronto). Todo un elenco de mecanismos electrónicos se instalaba en la-ya universalizada- "segunda piel", es decir, sobre la propia epidermis y/o en la ropa del consumidor, requiriendo el uso de procedimientos de naturaleza científica basados en la nanotecnología.

Desde 2006, el proyecto EGO, bajo denominación Samsung Ego Innovation Project a partir de 2013, desplegado en la Mercedes-Benz Fashion Week Madrid, se convierte en una firme apuesta por "la tecnología aplicada a la moda en cualquiera de sus facetas" (Samsung Ego Innovation Project, 2017). "Un holograma, un cubo y su musa, la modelo Aaliyah Rosales, son los tres pilares de la colección que abre el Samsung Ego de 2017”, a cargo de la empresa Abrahamsson. Una atípica intervención para la cual la artista digital Claudia Maté y el estudio Paraddax Lab diseñan una serie de avatares de la modelo que se proyectan en el desfile a modo de hologramas. Asimismo, los invitados al evento participan de manera activa en este espectáculo, colocando sobre su smartphone "una pirámide de cristal enmarcada en un rectángulo" -entregada por los organizadores- que permite "la reproducción del holograma en dos mitades, pudiendo contemplar en sus triángulos a la modelo desfilando" (López, 2016). 


\subsection{Objetivos}

Revisado el contexto y anotados algunos de los parámetros que acreditan la convivencia argumental, metodológica e instrumental, en el plano creativo, de las disciplinas constatadas en este estudio (comunicación y moda), cabe ahora registrar los objetivos planteados.

a) Realizar una inmersión en el ámbito creativo de la moda, limitada a propuestas expositivas y persuasivas particulares de las firmas Chanel y Gaultier, a través de paradigmas comunicativos que plantean la existencia de intervenciones en este campo cuyo progreso denota la asistencia de factores transmedia.

b) Justificar cómo estas intervenciones, cuyo origen y fin natural no atienden a un supuesto explícitamente transmedia, franquean el perímetro expositivo de la pasarela física para adentrarse en un espacio mediático heterogéneo que optimiza el valor del producto, convirtiéndolo en "protagonista" de un guion que se expande en los canales comunicativos.

c) Manifestar la excelente contribución informativa que revela el uso de bienes iconográficos, en sus nuevos formatos y soportes digitales, dentro de las fases creativas que contemplan la ideación y consiguiente evolución del producto asociado al ámbito de la moda y áreas afines.

d) En matices persuasivos, argumentar de qué manera la intermediación de factores transmedia en el desarrollo y la difusión de la obra gestada en el recinto creativo de la moda enriquece la -ya mencionada- excelencia del producto integrado en esta y, por tanto, de la marca comercial que lo asume.

e) Enlazando con el anterior propósito, evidenciar cómo esa introducción de metodologías transmedia, además de fortalecer la cualidad funcional/estética del producto y el posicionamiento de la marca, refuerza y propaga la línea estilística del autor. En este sentido, será importante considerar la adjetivación como obra de arte que debe aplicarse, en ocasiones, al producto y su guion.

\subsection{Metodología}

La metodología empleada en la presente investigación atiende al estudio de diferentes casos enmarcados en el territorio creativo de la moda, estableciéndose evidencias que corroboran una expansión narrativa de esta disciplina hacia los dominios comunicativos. Así, partiendo del universo estilístico de dos marcas de alta costura, como Chanel y Gaultier, se examinarán diversas intervenciones exclusivas de ambas marcas cuya relevancia salva las fronteras naturales que confinan el producto a un escenario físico (sea la pasarela, o la composición aislada y realista del producto), para adentrarse en la condición más mediática a la que se puede someter su difusión.

Una metodología, de naturaleza gráfica y alcance persuasivo, envuelta en los patrones comunicativos que prevé una sistemática transmedia, requerida -cada vez más- por las disciplinas que impulsan las competencias artísticas y promocionales de los bienes vinculados al sector textil (por ejemplo, el prêt-à-porter) y a divisiones contiguas, como pueda 
ser la cosmética. Entre estas disciplinas destacan, especialmente, el diseño y la dirección de arte; pero también otras de identidad tecnológica, como la realidad virtual, surgidas para ampliar la capacidad sensorial del ser humano.

De este modo, acotando el marco de actuación previsto en este estudio, sería importante señalar:

a) Que la secuencia de análisis acogería una revisión de correspondencias transmedia, extraídas de intervenciones tales como desfiles, performances o de la propia difusión en medios de productos específicos del ámbito de la moda y sus derivados.

b) Que la instrumentación de este análisis quedaría al amparo de la narrativa visual, siendo la imagen -en múltiples formatos- el recurso perceptible que arbitre la interacción que se decreta entre un usuario ávido de información y el canal de exposición del producto.

\section{Casos de estudio. El sumario transmedia en los dominios de Chanel y Gaultier}

Proyectos como Thierry Mugler's Fashion Show, The Brave New Unwired World Fashion Technology Show o EGO, antes analizados, corroboran hasta qué punto "la producción narrativa podría ser considerada una rama del diseño - el diseño narrativo- caracterizada por la planificación del relato más allá de un único medio o lenguaje” (Scolari, 2013: 278).

En este tipo de propuestas, la confluencia de dos mundos, el industrial -referenciado en la moda-y el tecnológico -plasmado en la computación-, se instrumenta y regula a través de procesos de reproducción gráfica digital, como pueda ser el diseño asistido por ordenador (CAD), quedando así solventada la parte técnica. En la vertiente argumental, el propio guion, no siempre cerrado de manera unilateral por el autor, se vertebraría; siendo necesario, como indica -metafóricamente- C. Scolari (2013: 278), orientar "un ojo a la creación de mundos y otro a la recuperación de los contenidos generados por los usuarios". De este modo, el usuario participa de manera abierta y activa en el diseño del sumario donde se instala la difusión del producto.

Los casos de estudio que se presentan dentro de esta fase analítica, con sus correspondientes propuestas creativas y repercusiones en el plano comunicativo, atienden a similares procesos de diseño. Nacen en un territorio ancestral, como es el ámbito de la moda, evolucionando de manera extraordinaria gracias a las valiosas aportaciones que realizan sus principales interlocutores: K. Lagerfeld y J. P. Gaultier. Dos prestigiosos diseñadores que renuevan continuamente la producción particular de sus correspondientes marcas, apelando a la tradición conceptual de la disciplina para justificar con nuevas herramientas un estilo personal inconfundible.

Instruido en el taller de Balmain, madurando su obra en Fendi y Chanel, Lagerfeld accede como fotógrafo al medio creativo de la moda. Por su parte, Gaultier, formado en el estudio del geómetra y vanguardista P. Cardin, no solo subscribe la visión y el estilo futurista del modisto italofrancés, sino también la innegable capacidad de generar y diversificar las 
líneas de producto, aplicando su marchamo propio: si cabe, un planteamiento transmedia auténticamente empresarial, fecundado con estrategias de branding.

Uno y otro, conocedores, asimismo, del incuestionable papel que juega la imagen en tareas de diseño y dirección de arte. Disciplinas cuya relación natural en el desarrollo del proyecto comunicativo, manejando componentes tipográficos, fotográficos y de la ilustración, favorece el establecimiento de los estándares persuasivos propios de la publicidad, en cualquiera de sus áreas. Publicidad entendida por Lagerfeld como "una de las formas de expresión contemporáneas más importantes", realizando intervenciones de esta naturaleza en Fendi o en Chanel que le permiten definirse como "un publicista sin agencia”, pues, parafraseando al propio modisto, "tampoco la necesita, por ser él mismo su mejor cliente" (Collado, 2011).

Actualmente, el diseño y la manufactura asistidos por ordenador no plantean exclusivamente funciones de esquematización técnica (CAD), así como de fabricación del producto (CAM); la imagen 3D no solo recrea gráficamente la realidad física del producto a diseñar; la arquitectura de interiores no proyecta simplemente la pasarela que recorren los maniquís; el relato que da forma a la línea estilística de la colección no pervive únicamente en ese espacio diseñado para su exhibición. Hoy, estas y otras directrices creativas y tecnologías han evolucionado, arraigando firmemente en el cosmos -en las fases- de la narrativa transmedia como iniciadores de un argumento que se expande en el tiempo, la forma y-ahora- en los medios.

Con todo, a continuación, se analiza la obra que prospera en dos universos creativos de la moda, apelando a la dirección de arte de autores como Lagerfeld -y, en menor medida, de Baz Luhrmann-, en el caso de Chanel; así como a la actividad de diseño desarrollada por Gaultier, en la empresa que lleva su mismo nombre. Es importante señalar que el bloque analítico de estos casos de estudio se introduce y alcanza una mayor extensión en cuanto a contenidos en la revisión de las intervenciones creativas vinculadas a Chanel, ya que su longevidad y transcendencia se ha visto refrendada no solo en la peculiaridad de sus productos, sino también en su versátil y prolongada expansión mediática. Por otra parte, la incorporación de Gaultier a este estudio resulta de la interesante faceta investigadora que aporta a la línea estilística de sus colecciones para alta costura, complementada con las grandes campañas de publicidad y marketing online que desarrolla para sus populares perfumes.

En cualquier caso, direcciones artísticas fijadas en contextos de moda y comunicación, que se extienden desde la génesis material del producto hasta su virtualización y difusión digital, evolucionando en ese recorrido a modo de proyecto transmedia.

\subsection{Chanel: la expansión mediática de un icono}

En 1857, Charles F. Worth abre su atelier en el número 7 de la rue de la Paix (París). El entusiasmo empresarial del inglés sería secundado, entre otras marcas en ciernes, por Doucet en 1880, Lanvin en 1909 y por una emprendedora Gabrielle Chanel, quien -en 1910- ubicaría su tienda de sombreros (Chanel Modes) en el número 21 de la rue Cambon. Nacía la alta costura (haute couture). 
"Bajo la iniciativa de Worth, la moda accede a la era moderna: se convierte en una empresa de creación, pero también en un espectáculo publicitario" (Lipovetsky, 2009: 79). Una doble vertiente-reducida a premisas empresariales y comunicativas-inmejorablemente administrada por Chanel, amparándose "durante mucho tiempo en su rol de 'emperatriz' antes de representar el papel de 'reina madre' de la costura” (Sicard, 2007: 88). Germinaba, de este modo, una rutina expositiva que promulgaba la posibilidad de trasladar a la pasarela los originales estilismos de la firma, proyectándolos igualmente a los mass media vigentes.

Dos reglas que concedían a la icónica little black jacket, la chaquetita negra de tweed diseñada por Mademoiselle Gabrielle en 1926, lucir por igual su "atrevida" austeridad de líneas tanto en los salones de alta costura de Cambon como en la portada de Vogue. En un periodo de entreguerras, donde se mostraba la realidad cotidiana de una población sumida en una grave crisis política, social y económica, los medios de comunicación recogían en su espacio una temática informativa, la moda, provista de una significativa repercusión cultural.

Transcurriría entonces un cuarto de siglo, hasta que uno de los grandes iconos femeninos del momento "confesase" a la revista Life su pasión por la fragancia creada a base de jazmín de Grasse por el perfumista de origen ruso, E. Beaux. Y la entrada en un nuevo milenio, para que esa misma celebrity que cubría su cuerpo con Chanel No5, Marilyn Monroe, figurase en el metraje digital de los anuncios de la marca francesa.

A las intervenciones publicitarias dirigidas por Luhrmann en 2004 y 2014 para Chanel No5, se incorporaba Inside Chanel. Un microsite que describe la evolución histórica de la marca aplicando una estructura narrativa de incuestionable calado literario. Sin duda, un espacio idóneo para la expansión comunicativa de sus productos y de la propia entidad, reforzado con "una estrategia de contenidos muy bien orquestada, y con una dirección creativa brillante y coherente al máximo con su identidad de marca, que, además, es omnicanal" (Comunicare, 2014).

Interpretada -a título póstumo- por la genuina “ambición rubia”, la campaña de Navidad 2013 de Chanel, titulada Marilyn y $N^{\circ}$, atiende a un spot de identidad fílmica documental. En matices identitarios de la marca y de su protagonista, este anuncio se presenta como un interesante emplazamiento publicitario del producto, mostrando escenarios y personas que formaron parte de la controvertida existencia personal y artística de Marilyn. Un exquisito argumento, cuya narrativa audiovisual conjuga las instantáneas en blanco y negro tomadas a la diva por E. Feingersh, con titulares en grotescas y subtítulos en romanas; vídeo documental, con sonido en V.O. de los personajes; así como una sencilla, pero sugerente, banda sonora.

Esta pieza publicitaria se transforma en un original reclamo histórico que relata el "idilio" entre la actriz y la emblemática fragancia, gracias a un guion consumado a modo de timeline transmedia en el que se ensamblan inmejorablemente diversos emblemas del patrimonio comunicativo: prensa escrita, aludiendo a Life, Modern Screen y Marie Claire; así como un aparato magnetófono y secuencias televisivas y cinematográficas, entre otros bienes informativos. La dirección de arte 
del spot, reducida a una meticulosa fusión de escenas, plantea un cosmos narrativo independiente -pero clarificador de la historia- en cada uno de los planos; conformando, en su totalidad, una pieza desplegada sobre un único argumento de analogía transmedia, cuya "producción salta de los medios digitales a un medio tradicional, como es la televisión. Ni que decir tiene que el éxito está asegurado, ya que ha sido vista y compartida por millones de personas en todo el mundo a través de las redes sociales" (Comunicare, 2014).

\subsection{Chanel Airlines sobre la "terminal" transmedia}

Conocedor de la necesaria complicidad que se da entre comunicación y moda, principalmente en estrategias publicitarias, Lagerfeld acomete otras vías profesionales paralelas a las propias que particularizan el diseño de moda. Fotógrafo, editor e ilustrador, entre otros perfiles, siempre ha asegurado que "le interesan casi todos los aspectos de la cultura, pues siente que todos le influyen de alguna manera". Para este polifacético creador "no existe una regla sobre lo que es inspirador y cómo puede afectarle", siendo que lo más importante "es observarlo todo, para luego olvidarte de ello y rehacerlo a tu modo" (Díaz, 2015).

En 2014 dirige Reincarnation, un film para Chanel estrenado en Salzburgo y publicado en Chanel.com. Esta experiencia de Lagerfeld en el medio fílmico se materializa como complemento audiovisual a la Colección Métiers d'Art París-Salzburgo 2014-15, corroborando, de este modo, la convergencia de soportes y medios que se dan cita en el proceso de creación y difusión de los recursos propios de esta prolífica disciplina del diseño industrial.

Ya sea en esta intervención, dotada de una clara influencia cinematográfica que se expande a un espacio físico y a Internet, o en la descrita a continuación, Chanel Airlines, en la que concurren las principales áreas del diseño dentro de una de las más teatralizadas puestas en escena de la firma, el kaiser de la moda despliega los valores más interesantes de una disciplina, la dirección de arte, que realiza sustanciales aportaciones técnicas al progreso de proyectos de naturaleza transmedia.

6 de octubre de 2015, aeropuerto París-Cambon. "Bajo el techo de vidrio del Gran Palacio, la Colección Prêt-à-Porter Primavera-verano 2016 de Chanel desfila a lo largo de los mostradores de facturación. Pasajeros y azafatas de Chanel Airlines exhiben alrededor de 99 looks" (Prodhon, 2015). Ese día, Lagerfeld reemplaza este majestuoso edificio, construido para albergar la Exposición Universal de 1900, por una refinada instalación que aloja una elegante escenografía aeroportuaria, difícilmente reproducible con tanta exquisitez en el que sería su emplazamiento natural.

El simbolismo reflejado en tan exclusiva "terminal de la moda" se confecciona -como ya se ha mencionado- a partir de una fusión de parcelas del diseño que ceden la iconografía de su capital creativo al registro de un libreto idóneamente documentado. La mente inquisitiva de Lagerfeld construye aquí su propia "galaxia" transmedia de la moda, invitando al espectador a una performance que expone -dentro de un contexto artístico- la cotidianeidad de un aeropuerto, con los códigos visuales propios de la aviación civil estandarizados en las tres divisiones principales del diseño: 
a) Diseño gráfico (editorial)

Chanel convierte el evento en una muestra de su potencial corporativo, estampando su monograma y la tipografía Couture en tarjetas de embarque, invitaciones, carros de equipaje, señalética, etc. Al margen de estos soportes físicos, "la tecnología posibilita también nuevos modelos económicos y de distribución con un claro impacto en las cuestiones de diseño" (Zapaterra, 2008: 189). Así, con hashtags sobre el evento, como \#ChanelAirlines o \#ChanelSpringSummer2016, las redes sociales (Twitter, Facebook e Instagram) difundían sincrónicamente todos los pormenores del acto y se generaban, a la par, los canales que adecuaban la atemporalidad del acontecimiento.

b) Diseño industrial

Una rica labor de patronaje y estudio de materiales incorporaba a la colección tejidos estampados -entre otros grafismos- con los códigos alfanuméricos centelleantes que emulan los datos registrados en las pantallas de información. Asimismo, los modelos de calzado que portaban estos viajeros ficticios se adornaban con luces LED, simulando el sistema de iluminación instalado en la pista de aterrizaje.

c) Diseño urbanístico

La ficticia puerta de embarque, tipografiada en su dintel con el legendario "No 5" del perfume, es el punto de inicio de la teatralizada ruta que fija Lagerfeld para sumergir a los espectadores en una escenografía aeroportuaria. Dentro, la platea que acoge a los invitados al evento se orienta hacia un escenario en el que se ubican mostradores de facturación, zonas de espera, pantallas informativas, etc. Detalles, todos, mimetizados con los recursos corporativos de la firma parisina.

Esta intermediación de diversos referentes del diseño gráfico (editorial), industrial y urbanístico dentro de un único argumento pondera la prolongación de la narrativa transmedia, proponiendo una acepción que se fundamenta en la transversalidad y la contribución que ejercen las áreas creativas involucradas (las tres grandes áreas del diseño) en la construcción del discurso audiovisual. Lo que L. Manovich (2011: 57) denomina como "cultura de la información. Un concepto que cabe entenderlo como paralelismo con otro, que es la cultura visual, y que aborda el modo en que la información se presenta en los diferentes escenarios y objetos culturales". Algunos de los modelos informativos enunciados entonces por Manovich están presentes en Chanel Airlines. Por ejemplo, "las pantallas de aeropuertos y los menús en pantalla de la televisión".

Un testimonio que encierra principios propios del lenguaje transmedia, pues el propio Manovich (2011: 57) "sitúa los nuevos medios en relación con muchas otras áreas de la cultura, pasadas y presentes, con otras tradiciones artísticas y mediáticas, con sus lenguajes y estrategias visuales para organizar la información y estructurar la experiencia del espectador" y, especialmente, con "la cultura visual contemporánea, con la organización interna, la iconografía e iconología y con la experiencia del espectador en diversos escenarios visuales de nuestra cultura, como son la publicidad y la moda." 
En la mente del creador, en este caso Lagerfeld, el desarrollo de la obra se hilvana atendiendo a factores propios de la percepción espacial. "En la representación espacial de la historia del discurso se da un espacio explícito (on, el que se ve), el que percibe el lector o espectador, y otro implícito (off, el que no se ve, pero se imagina), fuera de los márgenes de la pantalla o del escenario. Parte del espacio implícito puede explicitarse" (Moreno, 2003: 59). De este modo, la variante explícita de la intervención de Lagerfeld en Chanel Airlines queda patente en el escenario que diseña dentro del Gran Palacio de París, mientras que la implícita se instala en los canales comunicativos conectados simultáneamente a la actividad que genera el propio sumario.

"Este juego entre el espacio explícito y el implícito facilita la reconstrucción artificial de infinidad de espacios mediante la colaboración directa de los espectadores y su imaginación”. De hecho, continua I. Moreno (2003: 59), "los medios audiovisuales no explicitan todo el espacio, sino que se limitan a mostrar la parte que necesitan para cumplir la función narrativa que desempeña en el relato".

Ciñéndose a las palabras de S. Dixon, Lagerfeld realiza una labor de "investigación, como es debido, para inspirar a la gente; editando y refinando referencias culturales para crear algo unificador y nuevo" (Seddon, 2010: 20). Así, el modisto justifica nuevamente la posición que adopta la dirección de arte en el plano creativo del diseño de moda, contribuyendo al valor persuasivo que denota una entidad cuyo icono distintivo enlaza dos "ces" invertidas en su monograma. Un matiz corporativo que, a modo de metáfora y en plena era transmedia, adquiere, por un lado, una interpretación puramente técnica basada en la recreación del par estereoscópico necesario para reproducir como anáglifo una escena en 3D, y por otro, un "guiño" comunicativo a la confluencia de medios y formatos de un sello que apuesta por la elegancia y la originalidad sobre la pasarela, revalorizando la marca con inigualables campañas publicitarias.

\subsection{Chanel: la virtualización del sumario publicitario}

"El acto de la visión es un proceso dinámico y creativo, capaz de transmitir una percepción tridimensional estable de las imágenes en movimiento constitutivas de nuestro mundo visual” (Ching, 2007: 4). Un proceso, perfectamente implementado en las recreaciones visuales desplegadas en proyección esférica, características de los vídeos inmersivos o 360.

Esta "secuela" de la realidad virtual, materializada físicamente en la pantalla de un dispositivo digital (ordenador, smartphone o tableta portátil), permite al usuario orbitar libremente dentro de un espacio envolvente, siguiendo un guion que ajusta él mismo de manera sincrónica. Un formato cuyo proceso constructivo es heredado -en parte- de procedimientos clásicos como la perspectiva (y así lo conciben las disciplinas que ejercen labores técnicas de ingeniería), siendo convenido por las áreas de la comunicación como un eficaz reclamo para la difusión del producto.

Conocedora de la trascendencia del marketing y la publicidad digital online soportados en medios portables, la casa Chanel ha incluido dichas estrategias interactivas en la difusión comercial de sus productos. Ahora bien, por encima de 
las preminencias comunicativas del soporte, la compañía francesa siempre ha velado por fraguar una dirección de arte sublime, dotada de un lenguaje audiovisual cinematográfico que facilite exhibir una interacción precisa entre el usuario y el sumario que se ejecuta dentro de un espacio virtual.

En Le rouge crayon de couleur, spot para la colección de primavera 2017 de Chanel Beauty (Chanel, 2017), el planteamiento creativo, tanto a nivel de guion como de especificidades técnicas exigidas para su diseño y difusión, atiende a los citados criterios que determinan la elaboración de vídeos inmersivos.

Adentrados en el espacio virtual que se recrea en esta pieza publicitaria, y efectuando un rápido repaso a la narrativa visual a través del argumento y de los parámetros artísticos que lo nutren, se aprecia que toda la actividad se desenvuelve en el epicentro de un sencillo escenario compuesto por un carrusel de fotogramas. Una atmósfera velada a modo de grisalla, que vira parcialmente a color cuando la protagonista del anuncio, la modelo R. van Rompaey, esboza distintos pictogramas con un lápiz de labios de la marca. Producto que "guioniza" la trama de esta experiencia digital, componiendo junto a otros similares -en una clara simetría circular- un engranaje que actúa como eje motor de un particular “tiovivo", en cuya cúspide se estampa el monograma blanco de Chanel.

La experimentación dentro de ese entorno formado por elementos visuales y sonoros provistos de matices persuasivos, posiciona al usuario en un punto de observación e intervención privilegiado, desde donde controla la perspectiva de la escena, y con ello el plano de imagen asociado mecánicamente al argumento. Ahora bien, como sujeto activo de una trama audiovisual diseñada a propósito para acaparar instantáneamente su atención, este no solo interacciona en un marco cerrado y con unos actores determinados. "Gracias a la accesibilidad de los sitios web dedicados a compartir contenidos de vídeo, como YouTube, Vimeo o Flickr, las oportunidades para la divulgación y la promoción de obras videográficas son enormes" (Moore, 2013: 108); y el usuario, sin duda, conoce y utiliza estos canales de comunicación.

De este modo, cualquier interesado en la dimensión comercial, comunicativa y/o artística de Le rouge crayon de couleur podría acceder a sus contenidos triangulando los siguientes estadios, formatos y medios:

a) Experimental.

El guion, amoldado a un entorno inmersivo en formato vídeo $360^{\circ}$ y transmitido a través del canal de Chanel en YouTube.

b) Comercial.

La web donde se distribuye el producto, en la que cobra importancia la labor artística de K. Sadli (fotógrafo de moda) y J. Kaye (editor y estilista de moda).

c) Expositivo.

La pasarela, como realidad y epílogo lógico de toda intervención en esta disciplina, personificada aquí en el Spring-Summer 2017 Haute Couture show. 


\subsection{Gaultier: vanguardia y transmedia}

La incesante evolución de las corrientes artísticas y comunicativas en disciplinas como la ahora detallada, la moda, ha favorecido la descentralización de los métodos creativos y de los canales de difusión de una obra compuesta en inéditos formatos multimedia. Actualmente, el producto y-en su caso- el guion que le asiste, no se muestran aislados en un dominio físico, sometidos a la contemplación casi orwelliana que efectúa el espectador. Hoy, el caudal de recursos transmedia, nacido en "jurisdicciones" puramente narrativas, respalda la migración y el consiguiente emplazamiento del argumento en múltiples medios de comunicación.

En los apartados precedentes se han analizado evidencias creativas -principalmente, de orden iconográfico- que progresan de la vertiente expositiva a la estrictamente comunicativa, facilitando la diversificación del paradigma transmedia hacia territorios donde sigue primando la teatralización efectiva del argumento frente a su transformación en material audiovisual. El extenso marco de estudio e inserción de contenidos que ha significado el caso Chanel, se reduce en este cierre del bloque analítico, dedicado al eclecticismo que practica J. P. Gaultier en la elaboración y difusión de su obra más actual.

Una aproximación inicial a la contribución de Gaultier al hábitat creativo de la moda plantearía, en términos generales, una clara adscripción estilística a los géneros vanguardistas prosperados en la Bauhaus alemana o en el Futurismo, entre otras corrientes artísticas. Una tendencia profesional que germina en su expresiva "caja de costura" para dotar de contenido su -tantas veces-discutida línea de diseño y plantear asimismo originales formatos y canales para la difusión de la obra.

En las últimas campañas publicitarias, el enfant terrible de la alta costura ha empleado mecanismos y elementos transmedia que optimizan notablemente las cualidades naturales del producto, incrementando al mismo tiempo el interés persuasivo que emana del argumento ideado para su descripción. Una atracción, que el modisto francés ha incorporado, desde sus inicios en la disciplina, a la vestimenta y al carácter de sus personajes, creando, por un lado, un perfil femenino que se ajusta a una encorsetada doncella de reminiscencias pin-up, y por otro lado, un estereotipo masculino que simboliza en un adolescente ataviado con indumentaria marinera.

En abril de 2015, y en el mismo escenario elegido por Lagerfeld para ubicar la terminal de Chanel Airlines, el Gran Palacio de París, se inauguraba la muestra sobre Gaultier organizada por el Museo de Bellas Artes de Montreal. Para este evento, Moment Factory (estudio creativo especializado en el diseño y la producción de entornos multimedia) desarrolló una experiencia inmersiva que fue colocada en la L'escalier des muses, justo en el espacio que conecta los dos niveles de la exposición que acoge la obra del modisto.

"En consonancia con el punto de vista creativo de Gaultier, la obra que realiza Moment Factory convierte al espectador, al visitante, en el verdadero centro de atención, transformándolo -gráficamente- en una auténtica musa. De este modo, mediante un dispositivo interactivo, el visitante que accede a ese nivel de la escalera pue- 
de contemplar su silueta proyectada sobre un enorme lienzo, engalanada con los matices estilísticos de la obra del diseñador. En este escenario virtual, los flases de las cámaras y el sonido de la música sumergen al visitante en ese ambiente frenético tan particular que acontece en los desfiles de moda" (Boucher, 2015).

A nivel creativo, pero también sociológico, esta performance digital establece una relación directa entre la belleza singular de cada persona y su adaptación a los patrones pasajeros que impone la moda. La intermediación del recurso tecnológico favorece de manera sincrónica esa conexión entre usuario (visitante) y moda (intervención), otorgando simuladamente al individuo un privilegio exclusivo de una deidad: ser una musa.

La magnitud expositiva de esta instalación, que rinde merecida pleitesía al universo creativo de Gaultier, no se reduce únicamente al emplazamiento arquitectónico que alberga la propia muestra. La página web de Moment Factory reúne, en este caso, los testimonios fotográficos y teóricos que documentan una interesante pieza artística, cuya naturaleza estética y filosófica se simultánea, a modo de experiencia transmedia, sobre las paredes que recorren esa majestuosa escalera y en los conductos binarios de Internet.

\subsection{Dentro de la Factoría Gaultier}

Acceder a cualquiera de las secciones del dominio web de J. P. Gaultier supone una revisión virtual del talante artístico practicado por autores como O. Schlemmer, R. Lindner o, más recientemente, T. Bedard (DC Comics). Creador, este último, que ha colaborado en 2017 con el diseñador en la ilustración de las ediciones limitadas de sus fragancias, representando a dos superhéroes del cómic: Wonder Woman y Superman.

Dentro del amplio repertorio creativo de Gaultier, la geometría se instaura como uno de los principales pasaportes creativos que avala su obra en la pasarela. Un concepto, presente en las líneas horizontales de sus camisetas, como reminiscencia del ropaje que porta el bello marinero ideado por Fassbinder en Querelle (1982); en los cuadros escoceses de las faldas con las que desdibuja géneros y engalana al hombre en su colección And God Created Man (1985); o en los puntiagudos corsés (1983) que iconificaron en 1990 la imagen de Madonna en su Blond Ambition World Tour. La exquisitez en el uso y en los resultados del lenguaje gráfico utilizado en el patronaje de Gaultier, acredita, por tanto, una clara transposición de esos mismos principios creativos al medio de comunicación que los exhibe.

En su incesante labor investigadora, Gaultier descubre múltiples formatos gráficos aplicables al soporte, "extirpados" de los atributos de la marca que impregnan la epidermis del producto. Una constante heredada de su progenitor artístico, P. Cardin. De ahí, nace su obsesión por el packaging como molde contenedor de la idiosincrasia de un producto, provisto asimismo de argumento, ya sea un aroma o el propio cuerpo humano. El caso más evidente son los estandarizados relieves que esculpen la silueta de los frascos de sus perfumes, Le Male y Classique, "abrigados" por la geometría cilíndrica de su legendaria lata de aluminio. 
En 1962, A. Warhol iconificó pictóricamente este prosaico objeto, contribuyendo con su obra a la expansión comercial y al incremento del valor de marca de las sopas Campbell's. Pocos años después, en mayo de 1969, la revista Esquiremostraba en portada al artista estadounidense sumergiéndose dentro de la ya famosa lata. Adentrada la década de los setenta, Gaultier la ennoblecía, convirtiéndola en un emblema "inoxidable" de la casa, adaptable a cualquier espacio y estándar comunicativo.

De manera progresiva, este envoltorio se ha convertido en el elemento transmedia que compagina esencia y virtualidad en la parcela creativa que el diseñador francés dedica a la manufactura y difusión de sus aromas. Esencia, como realidad física que juega con el material y la forma, aportándole una segunda piel al frasco; virtualidad, en su faceta comunicativa, proponiendo una narrativa visual auspiciada por la morfología del propio icono, perfectamente reproducible y extrapolable a distintos medios, géneros y formatos.

Enlazando con la praxis publicitaria que retrata a este objeto dentro de la obra más reciente de Gaultier, será el vídeo inmersivo uno de los formatos que suscite un mayor interés en el diseñador. Certeza rotulada con el eslogan "Vivir la experiencia 360" (Gaultier, 2016a) dentro la cabecera de la aplicación web que se analiza a continuación. Un mensaje que invita al espectador a transformarse virtualmente en esta exclusiva lata, inducido por uno de los iconos femeninos del modisto, que, para la ocasión, se equipa con unas gafas de realidad virtual, superponiéndose a un fondo en el que aparece un enorme titular clarificador de la metodología empleada: "JPG 360".

Be the Bottle, denominación de esta experiencia creativa, aparece en 2016 -de manera sincrónica- tanto en la web como en las redes sociales y demás canales online de la marca francesa. Su condición artística armoniza con un trasfondo auténticamente publicitario, confluyendo en criterios de storytelling y de interacción gracias a la mediación de factores particulares de la geometría y la física, como la tercera y la cuarta dimensión, que actúan como catalizadores de la relación que acontece entre el usuario y la máquina (o aplicación digital).

Una conjunción de premisas, sujetas a las teorías, los métodos y los instrumentos concebidos alrededor de la tecnología que posibilita la reproducción de mundos virtuales (principalmente, la realidad virtual y la realidad aumentada) que, en el caso de esta producción publicitaria, ha sido implementada por Okio-Studio como práctica inmersiva en formato de vídeo $360^{\circ}$. Una empresa dedicada al desarrollo de aplicaciones para realidad virtual, que ha colaborado, entre otras, con la agencia Leo Burnett en la campaña Special Thé de Nestle y con Publicis para la creación de un test interactivo de conducción del Renault Koleos.

A nivel sensorial, el entramado espacial que diseña Okio-Studio se amolda a una proyección estereográfica, en cuyo interior se ubican diferentes personajes que deambulan alrededor de una línea de horizonte circular. El centro de esa circunferencia se corresponde con el lugar donde se sitúa el observador, personificado física y argumentalmente en el frasco de perfume Classique. La visión y la interacción de este espectador se ajustan a los principios clásicos de la perspectiva, pudiendo dirigir voluntariamente la cámara subjetiva que encarnan sus propios ojos, para consumar un sencillo guion 
que se adapta al espacio y a la identidad de los objetos y los actores que aparecen en la escena. Todos extraídos del inventario estilístico de Gaultier e incorporados a una tanda de microrrelatos, que se impregnan de la picaresca que precisa el ingenio del diseñador.

Antes de finalizar 2016, Gaultier amplía este interesante acceso al terreno más tecnificado de la creación transmedia con la plasmación de una obra de calado más conceptual. Destinada igualmente a la promoción de Le Male y Classique mediante el uso de mecanismos inmersivos, Be the Drop (Gaultier, 2016b) invita al usuario a realizar un viaje virtual, en el que transita a través del alambique que canaliza la elaboración del perfume, hasta su envasado final en el popular torso masculino o femenino que lo simboliza. En este caso, el usuario se trasforma en la gota que recorre esa "montaña rusa" vítrea, descubriendo en el trayecto la eclosión cromática de los materiales y las sensaciones que constituyen la savia de la fragancia.

Recogida, como la anterior, en formato de vídeo $360^{\circ}$, la acción que transcurre en Be the Drop se ejecuta al compás de la Casta Diva (aria de la ópera Norma, de V. Bellini), bajo una cúpula acristalada semejante a las que techan las estancias del Gran Palacio de París. Dos paradigmas, uno sonoro y otro icónico, afianzados en la obra de Gaultier, que actúan como conectores lógicos dentro del reducto transmedia que mediatiza la difusión de sus creaciones para la industria de la moda y la publicidad.

Como epílogo a estas dos propuestas, Be the Bottle y Be the Drop, señalar que ambas nacen de un guion común, la Factoría Gaultier (Gaultier, 2016c), difundido en el canal de la firma en Facebook y de manera más precisa en su dominio web. Este proyecto supone, en definitiva, una adaptación del imaginario simbólico y conceptual de Gaultier al registro de recursos multimedia integrados en el ámbito de la comunicación, que gestionan la conversión en soporte digital y posterior difusión de la obra.

Un análisis del espacio web donde se emplaza la Factoría Gaultier permite entrever una sucesión de códigos específicos del dialecto de las redes sociales, que introducen píldoras informativas audiovisuales. Se mezclan, de este modo, dos lenguajes diferentes: por un lado, el comunicativo, patente en etiquetas como \#jpgif, \#jpgworkers, \#bettylovesjpg, \#popeyelovesjpg, \#bethebottle o \#bethedrop; y por otro lado, el artístico, trascribiendo dichos hashtags -como titulares- en secuencias de vídeo, tipo time lapse o GIF animado, para ilustrar la atmósfera mecanizada por la que merodean y se relacionan los personajes del elenco Gaultier.

Factoría Gaultier y, en general, todos los canales que acogen la obra del modisto en Internet, componen hoy un extraordinario contenedor de evidencias testimoniales, técnicas y artísticas, que se consolida como el principal nodo digital dentro del esquema de medios que esgrime Gaultier para formalizar su estilo en el diseño de productos destinados al círculo de la moda y áreas limítrofes. El otro nodo -reafirmado en idéntico guion- será el territorio físico, personificado en la pasarela, así como en el punto de exposición y venta del producto. Idóneos, uno y otro, para trasmitir un mismo sumario 
de manera aislada, y con suficiente solvencia para conciliarlo dentro de un universo creativo unitario, evidenciando esa genuina narrativa transmedia "hilvanada" en el taller de Gaultier.

\section{Conclusiones}

El estudio de la forma, concretamente, de su representación visual dentro de un espacio real o ficticio, como aquel donde se desenvuelve la performance de la colección que cobra vida en una pasarela de moda, desencadena una serie de consecuencias que trascienden al ideal estrictamente creativo de esta disciplina.

Probablemente, la más importante de esas secuelas se decrete en el ámbito de la comunicación, teniendo en cuenta que las intervenciones artísticas aplicables al sector de la moda y a divisiones afines demandan una esmerada labor de difusión en medios que exhiba las cualidades del producto, promoviendo con ello el posicionamiento de la firma y la expansión de la línea estilística del creador. Así, los bienes digitales que componen el actual patrimonio multimedia, amparados principalmente en los atributos iconográficos, han suscitado la evolución y propagación comunicativa de un producto que se transforma en verdadera obra de arte bajo el influjo de artistas como Lagerfeld o Gaultier. Mecenas, ambos, de un estilo ecléctico en el que se fusionan medios, instrumentos y formatos audiovisuales, para transmitir la realidad y la simbología que asiste al producto y a la marca.

Estas mismas deducciones introducen los siguientes puntos, como cierre del apartado de conclusiones y de la propia investigación.

a) La exposición mediática del producto y su valedor tecnológico.

"Mientras que algunos diseñadores siguen optando por desfiles tipo atelier, otros permiten contemplarlos en directo a través de Internet, garantizando así una máxima exposición al público" (Moore, 2013: 57). La pasarela física migra, por tanto, a un dominio virtual, generándose una escenografía enriquecida gracias al empleo de imágenes sintéticas que comparten soporte digital con seres y objetos reales.

La irrupción de esta disciplina en los mundos virtuales, planteada a finales de los noventa por Mugler, incrementaba entonces los protocolos expositivos del producto en el firmamento de la moda. La socialización de la tecnología ha llegado también al front row de la pasarela, secundando a la creatividad y, en general, a la cultura de la moda a través de un vasto repertorio de instrumentos, métodos y canales de desarrollo y divulgación del producto, que encuentran en la imagen su mejor aliada.

b) La construcción de la marca a través de contenidos transmedia.

La imagen de marca se instituye como un "fenómeno sociocultural complejo" (Costa, 2007: 136), introduciéndose en un cosmos experiencial donde el producto, su representación icónica y su difusión requieren una sistematización de medios, metodologías e instrumentos que den cobertura al argumento que le asiste. 
En este sentido, el branded content adquiere una especial relevancia como generador de contenidos que serán segmentados por los medios sociales para, según G. Árias (2016: 52), “ajustarse al público real que nos interesa. La solución es crear un contenido transmedia, adaptando el mensaje a cada medio, a su forma y peculiaridades, así como al público al que pretendamos impactar".

Estos testimonios convierten al usuario en actor de un espectáculo visual donde el producto, la marca y el medio compendian el reclamo que precisa un auténtico guion transmedia. Motivo, por el cual "las marcas de moda están analizando la manera en que las nuevas tecnologías darán más visibilidad a su perfil, generarán un mayor número de ventas e incrementarán la lealtad de sus clientes" (Moore, 2013: 138).

Ahora bien, enlazando con el último argumento, cabría matizar que la construcción y exposición del producto -así como de "la imagen de marca"- podrían interpretarse como "una cuestión de psicología social, antes que un asunto de diseño" (Costa, 2007: 106).

c) Tecnología, ciencia y arte, catalizadores transmedia.

"Los avances tecnológicos han dado lugar a un cambio de paradigmas en la sociedad que hace que el entorno al que se enfrentan las personas hoy en día sea muy diferente al del pasado" (Hasegawa, 2015: 24). Hoy, la maleta no solo almacena ropa; también guarda los dispositivos digitales que han servido a su dueño para acceder a una de esas grandes bitácoras online de la moda, cuyos autores, conocidos bloggers e influencers como Ch. Ferragni (blog The Blonde Salad) o A. Song (blog Song of Style), exhiben en la red las tendencias creativas que se ajustan a su perfil personal y/o profesional.

De igual modo, esa creatividad transformada en grafismo que, pocas décadas atrás, transitaba del boceto conceptual trazado por el modisto al taller de patronaje, y de ahí -ya convertido en atuendo- a la propia pasarela, se asocia hoy a esa otra "creatividad secundaria", enunciada por A. Maslow a mitad del siglo pasado. Este reconocido autor, encuadrado en el ámbito de la psicología humanista, asociaba dicha expresión a "la producción racional de algo nuevo en el mundo, sea de orden técnico, científico o artístico, incluyendo muchas soluciones creativas y prácticas a problemas cotidianos" (Joas, 2013: 314).

Tecnología, ciencia y arte. Una tecnología fraguada en sistemáticas de realidad virtual y realidad aumentada, que introduce al usuario -al espectador- en un espacio y un guion envolventes. La praxis científica, que invita a este mismo sujeto a interactuar sensorialmente con el entorno ficticio que recrean los mecanismos digitales. El paradigma artístico, patente en el diseño de una atmósfera dotada de los objetos y la inventiva propia de un creador del Renacimiento, pero también en la teatralidad barroca que emana de la puesta en escena y la mediatización del argumento por parte del individuo que opera con la obra.

Tres factores que concurren en el proceso creativo y en la proyección mediática que acontece en el relato transmedia de una propuesta que se instala en el ámbito artístico y persuasivo de la moda. Y como tal quedan registrados en el 
hemisferio narrativo de los casos de estudio analizados en este artículo, ya sea en la recreación inmersiva de Le rouge crayon de couleur de Chanel o en la visita virtual a la Factoría Gaultier.

\section{Referencias bibliográficas}

Alvarado, M. (2008): “Vestir la moda. El lenguaje de la publicidad gráfica de Haut Couture”. En Crespo, P. (ed.): Moda, Comunicación y Sociedad. Sevilla: Comunicación Social Ediciones y Publicaciones.

Arias, G. (2016): “La fiebre del branded content”, Interactiva. Revista de la comunicación y el marketing digital, n. 178, p. 52.

Arzuaga, A. (2001): “iLa moda en los museos?”, El Cultural (El Mundo), 21 de marzo. [Consultado el 14/09/2016]. [Disponible en: http://www.elcultural.com/revista/arte/La-moda-en-los-museos/511].

BBC News (2000): “Techno clothing hits high Street”, Science (BBC News), 16 de agosto. [Consultado el 28/09/2016]. [Disponible en: http://news.bbc.co.uk/2/hi/science/nature/882254.stm].

Bezzola, T. (2008): “Luces por todas partes”. En Ewing, W. y Brandow, T. Edward Steichen. Fotografía de moda: los años de Condé Nast, 1923-1937 (catálogo exposición). Madrid: Armero.

Boucher, V. (2015): “Nouveau projet de Moment Factory: l'exposition Jean Paul Gaultier à Paris”, PR Newswire, 2 de abril. [Consultado el 04/10/2016]. [Disponible en: http://www.prnewswire.com/news-releases/nouveau-projet-de-momentfactory-lexposition-jean-paul-gaultier-a-paris-498454061.html].

Chanel (2017): “Le rouge crayon de couleur”, canal Chanel Facebook. [Consultado el 01/12/2016]. [Disponible en: https:// www.facebook.com/chanel/?fref=ts].

Ching, F. (2007): Dibujo y Proyecto. Barcelona: Gustavo Gili.

Collado, N. (2011): “Karl Lagerfeld: No es solo consumo, la moda crea empleo”, SModa (El País), 15 de octubre. [Consultado el 23/11/2016]. [Disponible en: http://smoda.elpais.com/moda/karl-lagerfeld-no-es-solo-consumo-la-moda-crea-empleo/].

Comunicare (2014): "Inside Chanel. Una estrategia de contenidos brillante", Comunicare marketing online, 21 de marzo. [Consultado el 24/11/2016]. [Disponible en: http://www.comunicare.es/inside-chanel-una-estrategia-de-contenidosbrillante/].

Costa, J. (2007): La imagen de marca. Un fenómeno social. Barcelona: Paidós.

Díaz, L. (2015): "Karl Lagerfeld se pasa al mundo del diseño de interiores en su nuevo proyecto", Vogue España, 5 de marzo. [Consultado el 01/12/2016]. [Disponible en: http://www.vogue./moda/news/articulos/ karl-lagerfeld-disenara-el-lobby-de-un-complejo-de-edificios-en-toronto/21896]. 
Dondis, D. (2004): La sintaxis de la imagen. Introducción al alfabeto visual. Barcelona: Gustavo Gili.

Fassbinder, R. (Dir.) (1982): Querelle. Alemania: Gaumont Film Company.

Gaultier, J. (2016a): “Be the Bottle”, J. P. Gaultier (web oficial). [Consultado el 12/01/2017]. [Disponible en: https://www. jeanpaulgaultier.com/es-es/bethebottle/].

Gaultier, J. (2016b): “Be the Drop”, J. P. Gaultier (web oficial). [Consultado el 16/01/2017]. [Disponible en: https://www. jeanpaulgaultier.com/es-es/bethedrop/].

Gaultier, J. (2016c): “Factoría Gaultier”, J. P. Gaultier (web oficial). [Consultado el 25/05/2017]. [Disponible en: https:// www.jeanpaulgaultier.com/es-es/the-factory/].

Hasegawa, M. (2015): Sí, eres creativo. Técnicas para potenciar tu creatividad. Sevilla: Advook.

Jiménez, J. (2008): La moda y la clase social en la era del consumo (Tesina). Barcelona: Departamento de Sociología, Universidad Autónoma de Barcelona.

Joas, H. (2013): La creatividad de la acción. Madrid: Centro de Investigaciones Sociológicas.

Lagerfeld, K. (2014): “Reincarnation”, Chanel News. [Consultado el 14/12/2016]. [Disponible en: http://chanel-news. chanel.com/es_ES/home/2014/11/teaser-video-clip.html].

Lipovetsky, G. (2009): El Imperio de lo efímero. La moda y su destino en las sociedades modernas. Barcelona: Anagrama.

López, M. (2016): “Los hologramas de la firma Abrahamsson toman el Samsung Ego de Cibeles", Tentaciones (El País), 20 de septiembre. [Consultado el 01/02/2017]. [Disponible en: http://elpais.com/elpais/2016/09/19/ tentaciones/1474301096_435113.html].

Manovich, L. (2011): El lenguaje de los nuevos medios de comunicación. La imagen en la era digital. Barcelona: Paidós.

Moore, W. (2013): Promoción de moda. Barcelona: Gustavo Gili.

Moreno, I. (2003): Narrativa audiovisual publicitaria. Barcelona: Paidós.

Pérez, J. et al. (1992): La seducción de la opulencia: publicidad, moda y consumo. Barcelona: Paidós.

Pipes, A. (2008): Dibujo para diseñadores: Técnicas, bocetos de concepto, sistemas informáticos, ilustración, medios, presentaciones, diseño por ordenador. Barcelona: Blume. 
Prodhon, F. (2015): “Chanel Airlines. Colección prêt-à-porter, primavera-verano 2016”, Chanel News, 7 de octubre. [Consultado el 15/12/2016]. [Disponible en: http://chanel-news.chanel.com/es_ES/home/2015/10/springsummer-2016-ready-to-wear-collection-chanel-airlines.html].

SamsungEgoInnovationProject(2017): “Innovationproject”, Mercedes-BenzFashionWeek(webofficial),febrero.[Consultado el01/02/2017]. [Disponible en:http://www.ifema.es/mercedesbenzfwm_01/Ego/PremioSamsungEgoInnovationProyect/ index.htm].

Scolari, C. (2013): Narrativas Transmedia. Cuando todos los medios cuentan. Barcelona: Deusto.

Seddon, T. y Herriott, L. (2010): Dirección de arte. Proyectos impresos. Barcelona: Gustavo Gili.

Sicard, M. (2007): Lujo, mentiras y marketing ¿Cómo funcionan las marcas de lujo? Barcelona: Gustavo Gili.

Singier, S. (1998): “IMAGINA `98: Digital becomes integral. Thierry Mugler’s Fashion Show", Animation World Magazine, Issue 3.1, abril. [Consultado el 19/10/2016]. [Disponible en: http://www.awn.com/mag/issue3.1/3.1pages/3.1singier_ eng.html].

Torrecillas, T. (2015): “¿La moda es arte?”, SModa (El País), 22 de febrero. [Consultado el 23/11/2016]. [Disponible en: http://smoda.elpais.com/moda/la-moda-es-arte/].

Wong, W. (1991): Fundamentos del diseño bi-y tri-dimensional. Barcelona: Gustavo Gili.

Zapaterra, Y. (2008): Diseño editorial. Periódicos y revistas. Barcelona: Gustavo Gili. 